\title{
REDISTRIBUTION OF SYSTEMIC BLOOD FLOW IN PULMONARY STENOSIS
}

\author{
BY \\ R. J. SHEPHARD \\ From the Cardiac Department, Guy's Hospital \\ Received September 24, 1954
}

Measurements of blood flow by the direct Fick method at cardiac catheterization have shown that in conditions such as Fallot's tetralogy, the resting systemic flow is within normal limits (Ernsting and Shephard, 1951). In pure pulmonary stenosis the association of a closed ventricular septum with a stenosed valve gives a greater potential restriction of systemic flow, but in practice a large proportion of cases show a resting flow that is within normal limits (Campbell, 1954); and cases with an increased flow through the pulmonary circuit are receiving increasing recognition (Deuchar and Zak, 1952).

Despite the comparative rarity of a reduced systemic flow, it is a fact of clinical experience, recognized since the time of Morgagni (1769), that many cases of pure pulmonary stenosis show evidence of peripheral cyanosis even in the resting state. In the recent series of Campbell (1954), only 15 of 44 cases gave no history of cyanosis; there was good reason to believe that cyanosis was peripheral in type in most of the remaining 29, although in some a potentially patent foramen ovale may have opened under the stress of severe exercise. It must therefore be concluded that there is a selective restriction of blood flow to those sites where cyanosis is commonly observed, particularly the superficial tissues of the extremities.

In the present paper, the discrepancy between the clinical estimates of cyanosis and the calculated systemic blood flow is examined further, and evidence of a possible redistribution of systemic flow is sought by analysis of the oxygen content of the various mixed venous blood specimens obtained at cardiac catheterization.

\section{TECHNIQUE}

Cyanosis. The clinical grading of cyanosis is largely that described by Campbell (1948), but the scheme has been amplified to cover the range of peripheral cyanosis. The degrees recognized in the present paper are as follows:

0 . No cyanosis at any time.

$\frac{1}{4}$. Occasional cyanosis in cold weather.

$\frac{1}{2}$. Consistent cyanosis in cold weather.

$\frac{3}{4}$. Consistent cyanosis in cold weather and sometimes on exertion also.

1. Consistent cyanosis with cold weather and exertion.

2. Cyanosis apparent to trained observer at rest in warm room.

3. Cyanosis easily noticed by patient's friends.

4. Cyanosis gross.

Screening. An attempt has been made to grade pulmonary flow on the findings at fluoroscopy. Previous work by Campbell (1951) suggested that the degree of visible pulsation in the pulmonary 
vessels was related largely to the level of pulmonary flow. For the present purpose, note has been taken of the density of the lung fields and the degree of pulsation in the large pulmonary vessels, and four grades of flow have been recognized as follows:

1. Diminished density of lung fields.

2. Normal density of lung fields.

3. Increased pulsation of pulmonary vessels with apparently normal density, or increased density with apparently normal pulsation in pulmonary vessels.

4. Increase of both density and pulsation of pulmonary vessels.

Cardiac Catheterization. The technique of catheterization used in this hospital has already been described (Holling and Zak, 1950). Ninety-four per cent has been accepted as the lower limit for the oxygen saturation of arterial blood, breathing air.

\section{Relationship betweEn Cyanosis AND Flow}

Peripheral Nature of Cyanosis. Cyanosis has been estimated as indicated above. The figure adopted represents an average value, taking into account the patient's history and a number of examinations both in the out-patient department and in the wards. The relationship between this clinical estimate of cyanosis and the systemic blood flow as measured at cardiac catheterization is examined in Fig. 1. All of the cases illustrated were thought to have pure pulmonary stenosis,

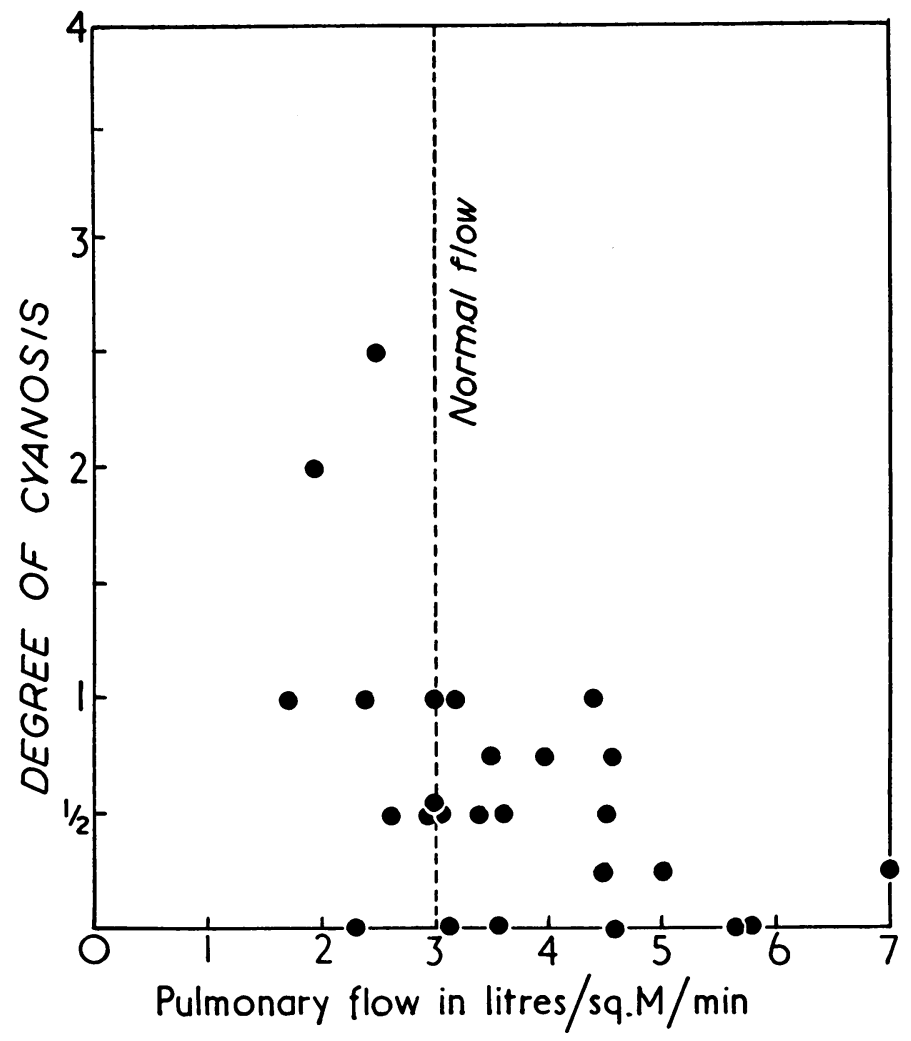

FIG. 1.-Relationship between level of pulmonary flow and cyanosis in 26 cases of pure pulmonary stenosis. Pulmonary flow measured at cardiac catheterization (direct Fick principle). Cyanosis estimated as described in text. Note that many patients with a normal pulmonary flow show some cyanosis. 
and the arterial oxygen saturation was within normal limits.* Any cyanosis that was observed in these patients, at least in the resting state, should therefore be peripheral in type.

The peripheral nature of the cyanosis was confirmed by the evidence of the patients, all except one of whom were certain that cyanosis was precipitated by exposure to cold. In five there was also occasional cyanosis with exertion, and here a temporary shunt through a patent foramen ovale may have contributed to the cyanosis. However, these findings are in marked contrast with the histories given by patients where catheterization confirmed the diagnosis of a right-to-left shunt through a patent foramen ovale, all of the latter group complaining of cyanosis after exertion (in one case- $0931, \mathrm{f}, 33$ years-when she was particularly hot).

Correlation of Cyanosis with Flow Rate measured by Fick method. The lower limit of the normal resting flow calculated by the Fick principle is probably about $3.01 . / \mathrm{sq} . \mathrm{m} . / \mathrm{min}$. (Cournand, 1945; Stead et al., 1945), and it can be seen that in the present group of pulmonary stenosis cases only 6 of 26 readings fall below the normal level. There is clearly a relationship between the grade of cyanosis and the level of flow, although the degree of correlation is not very close. Of the 6 patients with reduced flow, all except one (P310, m., 21 years) show a significant degree of cyanosis; the low flow rate in this case was a surprise, since he was leading a normal and very energetic life. It is certainly not due to technical errors, since he showed a normal oxygen consumption, and the low saturation of the pulmonary arterial blood was confirmed by two independent observers on different specimens. Further, the right ventricular pressure (systolic $140 \mathrm{~mm}$. $\mathrm{Hg}$ ) and the electrocardiogram ( $\mathrm{T}$ wave inversion to $\mathrm{V} 4$ ) confirm the severe nature of the stenosis in his case, and the absence of cyanosis is as yet unexplained.

Of the twenty patients with a normal or increased flow, quite a high proportion show some evidence of cyanosis, twelve being graded as $\frac{1}{2}-1$ degree. It might be thought that this discrepancy was due to a difference of state between the time at which cyanosis was observed and the time when the cardiac output was measured at catheterization, and it must be admitted that in one or two instances where a high cardiac output was recorded, there was some evidence of departure from the basal state, particularly an increase in metabolic rate. However, this is not true of the group as a whole, and typically the metabolic rate is within normal limits (Holling, 1952). Further evidence that the pulmonary flow is not altered by emotional disturbances during catheterization can be obtained by comparing the Fick flow rates with the estimate of flow made on fluoroscopy at out-patients.

Evidence from Fluoroscopy. A comparison of the pulmonary flow, calculated by the Fick principle, and the screening estimate of flow is given in Fig. 2. In general there is a satisfactory correspondence between the two values, suggesting that the level or pulmonary flow at outpatients corresponds with the flow at cardiac catheterization. The most serious discrepancy between screening impressions and calculated pulmonary flow was in a case with a patent foramen ovale $(\mathrm{O} 931, \mathrm{f}, 33$ years). Here the initial catheterization value $(4.81 \mathrm{l} / \mathrm{sq}$. $\mathrm{m}$./min.) was almost certainly erroneously high due to anxiety, and a second catheterization after valvotomy, when the patient admitted to being less nervous, showed that the cardiac output had actually fallen to just below the normal level (2.9 1./sq. $\mathrm{m}$./min.).

Functional Significance of Cyanosis. From the classical work of Lundsgaard and Van Slyke (1923) it is known that at least $5 \mathrm{~g}$. of reduced hæmoglobin per $100 \mathrm{ml}$. of blood are necessary to produce visible cyanosis. In conditions such as Fallot's tetralogy, where the hæmoglobin level of the blood is increased and there is also a right-to-left shunt, it is not surprising that the threshold for cyanosis is reached. However, where the hæmoglobin level is normal and there is no

* One case $(0468$, f, 8 years) shows an arterial oxygen saturation which is a little below the accepted normal value $(92 \cdot 2 \%)$, and in her case it is possible that a foramen ovale was forced open with exertion, although most of her cyanosis appeared to be peripheral. 


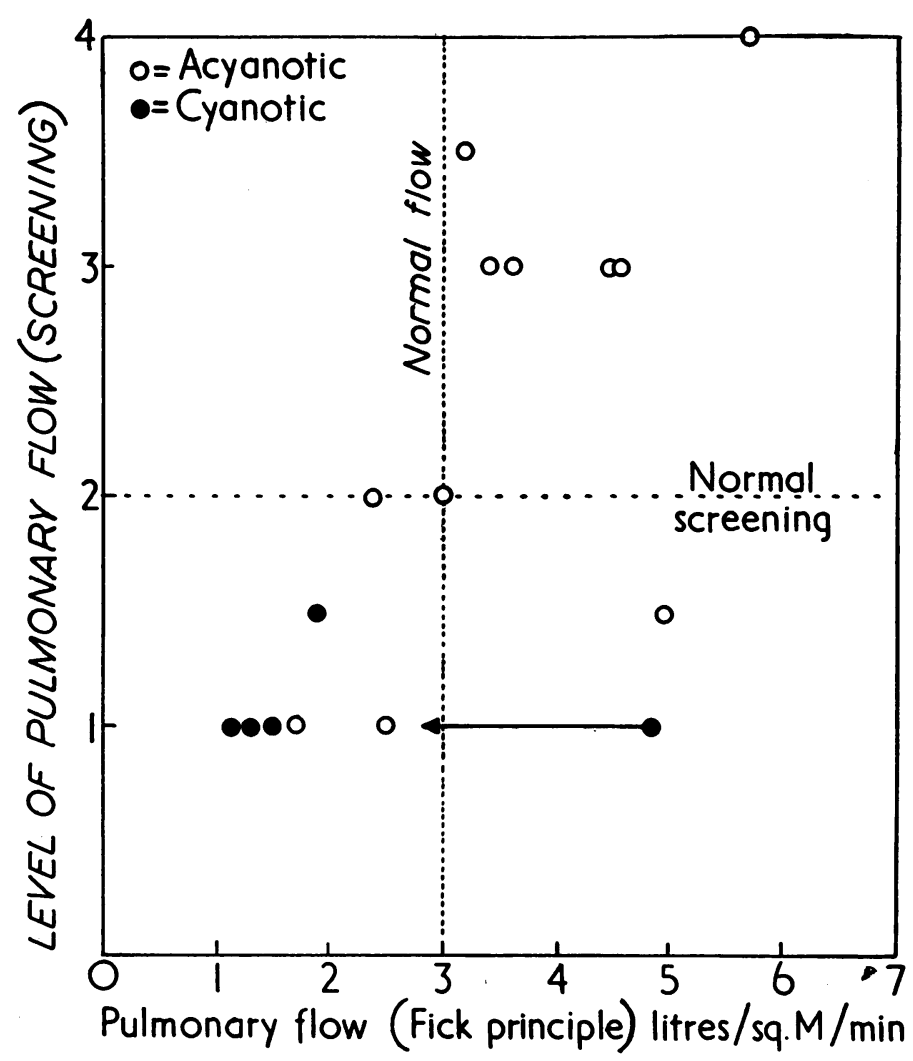

FIG. 2.-Relationship between screening and catheterization estimates of pulmonary flow in cases of pulmonary stenosis. In most instances there is a satisfactory correspondence between the two measurements.

intracardiac shunt, cyanosis cannot occur without a considerable reduction in the blood flow to a part. In normal subjects this may sometimes occur in the extremities in severe cold weather, and it has been suggested that in these circumstances a variation in calibre of the arterio-venous shunts (Grant, 1930) reduces the blood flow to the limbs in order to conserve body heat. It would seem that a similar mechanism operates in pulmonary stenosis, since in such cases the cyanosis is worse in cold weather; however, in many instances the sensitivity of this shunting mechanism appears to have been altered so that cyanosis appears at more normal external temperatures. The advantage of such an arrangement to the body economy has already been pointed out (Campbell, 1954). Although the resting cardiac output is usually within normal limits, in many cases of stenosis the right ventricular pressure is nearing a limiting value, so that during exercise little increase in systemic flow is possible. A limitation of blood flow to less vital areas of the body probably serves to conserve the limited cardiac reserve, and guards the more important organs from oxygen want under the conditions of exercise.

\section{Evidence of Redistribution of Caval Flow}

It was decided to test the hypothesis of a selective redistribution of blood flow by analysing the relative flow rates in the superior and inferior venæ cavæ of a group of pulmonary stenosis cases submitted for cardiac catheterization.

In a normal person, the oxygen saturation of blood samples taken from the superior vena cava 
is about 4 per cent less than the saturation of samples obtained from the inferior vena cava, and the composition of mixed venous blood can be explained by the mixing of these two streams in the ratio $2: 3$ (Hultgren et al., 1953). If an increased proportion of the systemic flow is directed to the head, the superior vena caval sample should reveal this change by a saturation approximating more closely to the mixed venous level, while the inferior vena caval sample should diverge more widely than normal from the mixed venous value.

Thirty-eight cases of pulmonary stenosis have been examined from this point of view-26 with pure pulmonary stenosis and 12 with patent foramen ovale. For purposes of comparison, a group of 16 cases of patent ductus arteriosus has been subjected to similar analysis: in this group the arterial saturation and resting systemic flow are normal, and there should be a more normal capacity to vary flow with exercise.

Estimation of "Mixed Venous" Oxygen Saturation. The first problem to settle is which of the various blood samples gives a reliable indication of the saturation of mixed venous blood. There is some evidence of laminar flow in the right atrium (Holling and Zak, 1950; Sirota and Gordon, 1954), and although the present results do not reveal this in terms of a systematic difference between the atrial and ventricular samples or in a larger standard deviation for the oxygen saturation of atrial samples (Table I), it has been thought wiser to limit the estimation of mixed venous saturation to values derived from the right ventricular and pulmonary arterial samples.

TABLE I

Average Oxygen Saturation of Right Atrial, Right Ventricular, and Pulmonary Arterial Blood Specimens, With Estimate of Standard Deviation of Single ObServation in Each Group

\begin{tabular}{|c|c|c|c|}
\hline Diagnosis & $\begin{array}{l}\text { Saturation of R.A. samples } \\
\text { (percentage) }\end{array}$ & $\begin{array}{l}\text { Saturation of R.V. samples } \\
\text { (percentage) }\end{array}$ & $\begin{array}{c}\text { Saturation of P.A. samples } \\
\text { (percentage) }\end{array}$ \\
\hline $\begin{array}{l}\text { Pure pulmonary stenosis } \\
\text { Pulmonary stenosis with } \\
\text { patent foramen ovale } \\
\text { Patent ductus arteriosus }\end{array}$ & $\begin{array}{c}68 \cdot 3 \\
S_{d} \pm 8 \cdot 5 \\
55 \cdot 6 \\
S_{d} \pm 14 \cdot 5 \\
69 \cdot 4 \\
S_{d} \pm 7 \cdot 6\end{array}$ & $\begin{array}{c}67 \cdot 8 \\
S_{d} \pm 9 \cdot 3 \\
56 \cdot 0 \\
S_{d} \pm 11 \cdot 3 \\
70 \cdot 5 \\
S_{d} \pm 6 \cdot 4\end{array}$ & $\begin{array}{c}68.0 \\
S_{d} \pm 8 \cdot 6 \\
49.9 \\
S_{d} \pm 20 \cdot 4 \\
\text { Increased by left-to-right } \\
\text { shunt }\end{array}$ \\
\hline
\end{tabular}

In severe pulmonary stenosis, the saturation of the pulmonary arterial specimen may be much lower than a specimen withdrawn simultaneously from the right ventricle, and this has been attributed to material obstruction of pulmonary flow by the catheter tip. Five of the present series appear to fall into this category (Table II), although the group as a whole shows no significant difference between right ventricular and pulmonary arterial samples. Thus in these five cases it

TABLE II

Difference in Oxygen Saturation between Right Ventricle and Pulmonary Artery in Five Cases of Pulmonary Stenosis With Low Resting Pulmonary Flow

\begin{tabular}{|c|c|c|c|c|c|}
\hline Case No. & Sex and age & $\begin{array}{l}\text { Pulmonary flow } \\
\text { (1./sq. } \mathrm{m} . / \mathrm{min} .)\end{array}$ & $\begin{array}{c}\text { Saturation of R.V. } \\
\text { sample } \\
\text { (percentage) }\end{array}$ & $\begin{array}{c}\text { Saturation of P.A. } \\
\text { sample } \\
\text { (percentage) }\end{array}$ & $\begin{array}{l}\text { Difference } \\
\text { P.A.-R.V. } \\
\text { (percentage) }\end{array}$ \\
\hline $\begin{array}{l}\text { O328 } \\
\text { O468 } \\
\text { P288 } \\
\text { O745 } \\
\text { O207 }\end{array}$ & $\begin{array}{lr}\mathbf{F} & 13 \\
\mathbf{F} & 9 \\
\mathbf{F} & 6 \\
\mathbf{F} & 19 \\
\mathbf{F} & 26\end{array}$ & $\begin{array}{l}1 \cdot 9 \\
2 \cdot 4 \\
2 \cdot 2 \\
3 \cdot 2 \\
2 \cdot 2\end{array}$ & $\begin{array}{l}49 \cdot 2 \\
53 \cdot 5 \\
61 \cdot 1 \\
52 \cdot 3 \\
47 \cdot 2\end{array}$ & $\begin{array}{l}40 \cdot 5 \\
33 \cdot 4 \\
48 \cdot 0 \\
43 \cdot 3 \\
22 \cdot 1\end{array}$ & $\begin{array}{r}-8 \cdot 7 \\
-20.1 \\
-13 \cdot 1 \\
-9.0 \\
-25 \cdot 1\end{array}$ \\
\hline
\end{tabular}


has been necessary to take the right ventricular samples alone as indicative of mixed venous saturation. In patent ductus arteriosus a similar procedure is necessary on account of the shunt into the pulmonary artery.

Changes in Caval Flow. Having decided upon the mixed venous oxygen saturation in this way, it is possible to measure the deviations of superior and inferior vena caval samples from the mixed venous value, and to compare the deviations with those expected on a $2: 3$ flow ratio. It can be seen (Table III) that in patent ductus arteriosus, the difference from the expected value is no greater

TABLE III

Deviations of Oxygen Saturation of Superior and Inferior Vena Caval Specimens from Saturation of Mixed Venous Blood-A Statistical Comparison with Values Expected on a $2: 3$ Flow Ratio in Great VEINS

\begin{tabular}{|c|c|c|c|c|c|c|}
\hline Diagnosis & Sample & $\begin{array}{c}\text { Number of } \\
\text { cases }\end{array}$ & $\begin{array}{c}\text { Deviation } \\
\text { from M.V.B } \\
\text { (percentage) }\end{array}$ & $\begin{array}{c}\text { Expected } \\
\text { deviation } \\
\text { (percentage) }\end{array}$ & $\begin{array}{l}\text { Difference } \\
\text { (percentage) }\end{array}$ & Probability \\
\hline $\begin{array}{l}\text { Pure pulmon- } \\
\text { ary stenosis }\end{array}$ & $\begin{array}{l}\text { S V.C. } \\
\text { I.V.C. }\end{array}$ & $\begin{array}{l}26 \\
26\end{array}$ & $\begin{array}{l}-0.02 \\
+4 \cdot 21\end{array}$ & $\begin{array}{l}-2 \cdot 54 \\
+1 \cdot 69\end{array}$ & $\begin{array}{l}+2.52 \text { s.e. } \pm 0.71 \\
+2.52 \text { s.e. } \pm 1.17\end{array}$ & $\begin{array}{r}0.001-0.01 \\
0.05-0.02\end{array}$ \\
\hline $\begin{array}{l}\text { Pulmonary } \\
\text { stenosis with } \\
\text { patent fora- } \\
\text { men ovale }\end{array}$ & $\begin{array}{l}\text { S.V.C. } \\
\text { I.V.C. }\end{array}$ & $\begin{array}{l}12 \\
12\end{array}$ & $\begin{array}{l}-3.90 \\
+4.69\end{array}$ & $\begin{array}{l}-5 \cdot 16 \\
+3 \cdot 43\end{array}$ & $\begin{array}{l}+1.26 \text { s.e. } \pm 2.28 \\
+1.26 \text { s.e. } \pm 1.50\end{array}$ & $\begin{array}{l}0.5-0.7 \\
0.5-0.3\end{array}$ \\
\hline $\begin{array}{l}\text { Patent ductus } \\
\text { arteriosus }\end{array}$ & $\begin{array}{l}\text { S.V.C. } \\
\text { I.V.C. }\end{array}$ & $\begin{array}{l}16 \\
16\end{array}$ & $\begin{array}{l}-1 \cdot 38 \\
+2 \cdot 88\end{array}$ & $\begin{array}{l}-2.56 \\
+1.70\end{array}$ & $\begin{array}{l}+1 \cdot 17 \text { s.e. } \pm 1 \cdot 15 \\
+1 \cdot 17 \text { s.e. } \pm 2 \cdot 14\end{array}$ & $\begin{array}{l}0.3 \\
0.5-0.7\end{array}$ \\
\hline
\end{tabular}

than could be explained on a chance variation (thus for the S.V.C. sample $P=0 \cdot 3$ ). However, in pure pulmonary stenosis, the departure from expectation is much larger, and of considerable significance (for the superior vena caval sample $P$ is in the range 0.01-0.001). Thus it is clear that in this condition the upper half of the body receives an unusually large proportion of the systemic blood flow. It is perhaps rather surprising that this finding is not repeated in pulmonary stenosis with a patent foramen ovale, for if anything the systemic flow in this group is smaller. However, it is possible that here oxygen differences are disturbed by the diversion of a proportion of caval flow to the left atrium.

\section{Discussion}

The above analysis gives clear evidence that in pure pulmonary stenosis the systemic blood flow shows an abnormal distribution, an increased proportion of the cardiac output reaching the upper half of the body. Further, it seems probable that this represents mainly an increase of flow to the head, since the arms and hands show a high incidence of peripheral cyanosis.

The importance of this redistribution during exercise has already been discussed. The degree of adaption which can be achieved by this mechanism is uncertain, but it is of some significance that whereas in Fallot's tetralogy hæmodynamic instability and other signs and symptoms of medullary hypoxia may appear during exercise (Shephard, 1954), in pulmonary stenosis such attacks are rare. Calculation of the mean systemic capillary oxygen tension (Houston and Riley, 1947; Ernsting and Shephard, 1951) reveals that the average degree of tissue hypoxia is very similar in the more severe forms of either condition, and the absence of attacks in pulmonary stenosis supports the view that a more favourable oxygen tension is maintained in the medullary centres by selective redistribution of the available cardiac output. 


\section{SUMMARY}

Pure pulmonary stenosis shows a high incidence of peripheral cyanosis, but despite this the cardiac output as measured by the direct Fick method at catheterization is typically within normal limits. Analysis of the caval blood samples in 26 cases of pure pulmonary stenosis, 12 cases of pulmonary stenosis with patent foramen ovale, and 16 cases of patent ductus arteriosus shows that in pure pulmonary stenosis the blood flow from the upper half of the body exceeds the normal value of 40 per cent of the cardiac output. The mechanism and importance of this redistribution during exercise are briefly considered.

I am greatly indebted to Dr. Campbell, who provided the data relating to screening and cyanosis from his personal records, and gave much helpful criticism in the preparation of this paper. My thanks are also due to the Department of Medical Illustration for their cooperation in producing the diagrams.

\section{REFERENCES}

Brown, J. W. (1950). Congenital Heart Disease. 2nd ed., Staples Press.

Campbeli, M. (1948). Guy's Hosp. Rep., 97, 1.

(1951). Brit. Heart J., 13, 438.

(1954). Brit, Heart J., 16, 273.

Cournand, A. (1945). Fed. Proc., 4, 207.

Deuchar, D. C., and Zak, G. (1952). Guy's Hosp. Rep., 101, 1.

Ernsting, J., and Shephard, R. J. (1951). J. Physiol., 112, 332.

Grant, R. T. (1930). Heart, 15, 527.

Holling, H. E. (1952). Clin. Sci., 11, 283.

- , and Zak. G. (1950). Brit. Heart J., 12, 153.

Houston, C. S., and Riley, R. L. (1947). Amer. J. Physiol., 149, 565.

Hultgren, H., Selzer, A., Purdy, A., Holman, E., and Gerbode, F. (1953). Circulation, 8, 15.

Lundsgaard, C., and Van Slyke, D. D. (1923). Cyanosis. Medicine Monographs (Baltimore).

Morgagni (1769). Quoted by Brown (1950).

Shephard, R. J. (1954). Guy's Hosp. Rep. In press.

Sirota, J. H., and Gordon, A. J. (1954). J. appl. Physiol., 5, 485.

Stead, E. A. Jr., Warren, J. V., Merrill, A. J., and Brannon, E. S. (1945). J. Clin. Inv., 24, 326. 